\title{
The Influencing Factors of Tourism Sharing Behaviours of WeChat Users and Practical Enlightenment
}

\author{
Yingying $\mathrm{Chen}^{1}$, Zhenghong $\mathrm{Yu}^{2}$, Qiuyue $\mathrm{Pan}^{3, *}$
}

\author{
${ }^{123}$ Xiamen University of Technology College of Culture and Tourism \\ ${ }^{*}$ Corresponding author. Email: 515615950@qq.com; qiuyuepan@sina.com
}

\begin{abstract}
With the continuous development of network technology, information sharing has become an important part of people's network life. Contemporary tourists are used to sharing their travel experience online in the form of pictures or words during tourism activities. In this paper, college students who share tourism experiences on the WeChat platform are taken as the research objects. Through the collation of the existing literature and questionnaires survey of college students, it is found that the significant factors that affect the tourism sharing of college students in WeChat include network status, personal privacy, travel experience and whether they are willing to share. According to the conclusion of this paper, we put forward practical enlightenment to tourist destinations and tourism merchants from two aspects: operation management and marketing.
\end{abstract}

Keywords: Tourism sharing behaviours, WeChat, Influencing factors, Management advices

\section{INTRODUCTION}

With the upgrading of the Internet and related technologies, sharing behaviours in the network has become a part of People's Daily life, and travel sharing is a common type of sharing. Nowadays, as a highly active group of network users, college students are connected with various online sharing behaviours every day. In addition to their own tourism sharing behaviours, college students also pay attention to others' tourism sharing, from which they can obtain the tourism information they need and interact with others to enhance their connection. The fundamental tenet of tourism development has changed from economic orientation to tourist-centered, which is also the development trend of China's tourism industry in the new era. The exploration of tourism sharing behaviours can further understand the psychological and behavioural characteristics of tourists and promote the development of tourism market.

\section{LITERATURE REVIEW}

\subsection{Factors influencing sharing behaviours of WeChat users}

Sharing information through WeChat is one of the important information behaviours of contemporary college students. Many scholars have discussed the influencing factors of this behaviour. By means of questionnaire survey, Zhang and Li (2015) conducted correlation analysis to find that there are three important factors that affect college students' WeChat sharing behaviours: self-identification, entertainment and social interaction. Among them, social interaction had the most significant impact on college students' sharing behaviours ${ }^{[1]}$. Yu (2017) found that entertainment, social activities, research and learning were the motivations of college students' WeChat sharing behaviours ${ }^{[2]} \cdot \mathrm{He}$ (2018) found that college students were the most active users of WeChat Moments and they shared WeChat out of self-satisfaction and social needs, and all had the intention of displaying a better self ${ }^{[3]}$. Huo and Jin (2019) concluded that WeChat users' information sharing behaviours were influenced by WeChat information, WeChat information 
environment, WeChat information technology and other factors from the perspective of information ecology ${ }^{[4]}$.

\subsection{Factors influencing sharing behaviours of WeChat users}

Foreign scholars started to study sharing behaviours earlier, including researches on knowledge sharing related to the hotel industry. There are many research results on tourism sharing abroad, and with the rapid development of information technology, the scope of research will continue to expand. For example, Scott and Laws (2006) explored the concept and its application of knowledge sharing related to tourism and the hotel industry ${ }^{[5]}$. Yoo and Gretzel (2010) found that the personality characteristics of tourists significantly affect their sharing and creation behaviours ${ }^{[6]}$. Munar et al. (2014) found that altruistic motivation and community-related motivation were most related to information sharing, and motivational factors varied according to content types and social media types ${ }^{[7]}$. Lehto et al. (2018) found that the emotional intensity of disabled tourists had an impact on their tourism sharing [8]. Kumar et.al (2021) pointed that the social capital dimensions (social ties, trust, reciprocity and shared vision) positively impact sharing intention on social media while identification doesn't impact the sharing intention ${ }^{[9]}$.

At present, there are little attention paid to WeChat tourism sharing behaviours in Chinese tourism academia. The researches on tourism sharing behaviours mainly focus on the sharing of non-acquaintance network such as virtual tourism communities and tourism Web sites. For example, Gao et al. (2016) used structural equation analysis to find that tourists spread online word of mouth because of high-quality products, services and environmental experience ${ }^{[10]}$. Wang et al. (2017) tested the effects of intrinsic motivation, extrinsic motivation, protected and acquired face orientation on tourism experience sharing intention and behaviours ${ }^{[11]}$. Zhao et al. (2018) found that in the case of spiritual reward, high level of material reward is not as effective as low level of material reward in stimulating re-sharing intention ${ }^{[12]}$.

Nowadays, more people inclined to share their travel experiences on WeChat. Research on tourism sharing should be carried out from multiple perspectives, so as to have a more comprehensive understanding of the travel sharing behaviors of college students WeChat users. Recently, Chen and Lin (2020) used grounded theory to comprehensively examine sharing behavior in tourism through social platforms. Their study show that influencing factors of tourism sharing including network, time, devices, social media, status of tourist, destination experience, working environment, privacy and response from friends ${ }^{[13]}$. Based on the existing research, this paper divides the factors affecting college students' travel sharing behaviors into four dimensions: demographic characteristics, individual cognition of external conditions and personality traits, and conducts questionnaire design according to these four dimensions.

\section{RESEARCH DESIGN AND IMPLEMENTATION}

\subsection{Questionnaire Design}

The questionnaire mainly includes the demographic characteristics of interviewees, such as gender, grade, monthly income, etc. Individual cognition, which includes sharing involvement and sharing motivation. External conditions include network conditions, mobile phone and other equipment conditions and other variables. Personality traits means whether tourists are willing to share their travel experiences. Specific variables were measured as follows.

\subsection{Variable Measurement}

In this paper, we believed that the factors influencing whether college students share or not through WeChat come from the individual dimension and the external environment dimension. The individual dimension includes individual cognition and personality traits. Therefore, these three aspects were respectively included in the logistic regression analysis equation for analysis. Firstly, individual cognition refers to the individual to a particular behaviour of subjective cognitive or insights, sharing motivation and involvement as measured variables. Secondly, individual personality traits, such as individual personality, preferences and so on, the specific measurement is entitled "whether willing to share ". Thirdly, the external environment refers to the external conditions perceived by an individual to affect the occurrence of a certain behaviours. Specific measurement variables include the network status, time, sharing equipment status, schedule conflict, selfsatisfied copywriting or pictures, travel companions' experience in the tourist destination and friends' response to travel sharing. In addition, demographic characteristics were also related to sharing intention, so demographic are more likely to have an impact on viewers, including gender, grade, income and travel frequency. Based on this, this study takes 'whether to carry out tourism sharing' as the dependent variable Y, which is a dichotomous variable and is a random variable with a value of 0 or 1 . When $Y=1$, it represents the behaviours of tourism sharing, $\mathrm{Y}=0$ means no tourism sharing behaviours. $\{\mathrm{X} 1, \mathrm{X} 2, \ldots, \mathrm{Xn}\}$ indicated the sequence of explanatory variables that might affect the tourism sharing behaviours, including the four categories of variables above and their coding conditions were shown in Table 1. 


\subsection{Research and Implementation}

The purpose of this study is to explore the influencing factors of tourism sharing among WeChat users of college students. In order to ensure the validity of the questionnaire, the question 'whether it is college students or not' was set for sample discrimination. The incomplete data samples were eliminated after the questionnaire recovery. Formal questionnaires were published on the platform of Questionnaire Star and distributed through WeChat, QQ and other social platforms. 201 questionnaires were collected. Since the research objects were college students, 159 valid questionnaires were obtained after eliminating the samples of non-college students.

Table 1. Variable measurement and its coding interpretation summary

\begin{tabular}{|c|c|c|c|}
\hline & $\begin{array}{l}\text { Explanatory } \\
\text { variable }\end{array}$ & Variable meaning & Variable coding \\
\hline $\begin{array}{l}\text { Explained } \\
\text { variable }\end{array}$ & $\mathrm{Y}$ & $\begin{array}{l}\text { Whether to share travel } \\
\text { on WeChat }\end{array}$ & $1=$ Yes; $0=$ no \\
\hline \multirow{4}{*}{$\begin{array}{l}\text { Demographic } \\
\text { characteristics } \\
\text { of distributors }\end{array}$} & $\mathrm{X} 1$ & Grade & $\begin{array}{c}1=\text { Freshman; } 2 \text { = Sophomore; } 3 \text { = Junior; } \\
4=\text { Senior year and above }\end{array}$ \\
\hline & $\mathrm{X} 2$ & Gender & 1=Male; 2=Female \\
\hline & $\mathrm{X} 3$ & Monthly income (RMB) & $\begin{array}{c}1=\text { Below } 2000 \text { yuan; } 2=2000-5000 \text { yuan; } \\
3=\text { Above } 5000 \text { yuan }\end{array}$ \\
\hline & $\mathrm{X} 4$ & $\begin{array}{l}\text { Travel frequency ( } \\
\text { Times/Year) }\end{array}$ & $\begin{array}{c}1=1-2 \text { times; } 2=\text { More than 3times } \\
\text { ( } 0 \text { was deleted as the research object that } \\
\text { did not meet the conditions) }\end{array}$ \\
\hline \multirow[b]{2}{*}{$\begin{array}{l}\text { Individual } \\
\text { cognitive }\end{array}$} & $\mathrm{X} 5$ & Sharing involvement & $\begin{array}{c}\text { Mean(Share importance, share pleasure, } \\
\text { share perception of risk) }\end{array}$ \\
\hline & $\mathrm{X} 6$ & Sharing motivation & $\begin{array}{c}\text { Continuous variables (9 motivations } \\
\text { correspond to } 9 \text { continuous variables) } \\
\text { X6-1 = Record \& recall \& keepsake; X6-2 = } \\
\text { Sharing feelings; X6-3 = Share beauty \& fun; } \\
\text { X6-4 = Show Yourself; X6-5 = strengthen } \\
\text { interaction with others; X6-6 = Seeking } \\
\text { attention; X6-7 = to provide others with } \\
\text { reference information; X6-8 = Seeking } \\
\text { approval; X6-9 = conformity }\end{array}$ \\
\hline \multirow{12}{*}{$\begin{array}{l}\text { External } \\
\text { condition }\end{array}$} & $\mathrm{X} 7$ & Network status & $1=$ affected; $0=$ unaffected \\
\hline & $\mathrm{X} 8$ & Leisure time & $1=$ affected; $0=$ unaffected \\
\hline & X9 & $\begin{array}{l}\text { Cell phone and other } \\
\text { equipment status }\end{array}$ & $1=$ affected; $0=$ unaffected \\
\hline & $\mathrm{X} 10$ & $\begin{array}{l}\text { Conflict with work or } \\
\text { school schedules }\end{array}$ & $1=$ affected; $0=$ unaffected \\
\hline & $\mathrm{X} 11$ & Individual privacy & $1=$ affected; $0=$ unaffected \\
\hline & $\mathrm{X} 12$ & Travel companion & $1=$ affected; $0=$ unaffected \\
\hline & $\mathrm{X} 13$ & $\begin{array}{c}\text { Experience of the tourist } \\
\text { destination }\end{array}$ & $1=$ affected; $0=$ unaffected \\
\hline & $\mathrm{X} 14$ & $\begin{array}{c}\text { How others respond to } \\
\text { sharing }\end{array}$ & $1=$ affected; $0=$ unaffected \\
\hline & $\mathrm{X} 15$ & $\begin{array}{c}\text { Whether there is a good } \\
\text { copy or photo }\end{array}$ & $1=$ affected; $0=$ unaffected \\
\hline & $\mathrm{X} 16$ & $\begin{array}{c}\text { Is there any material or } \\
\text { spiritual reward (e.g., } \\
\text { discount) }\end{array}$ & $1=$ affected; $0=$ unaffected \\
\hline & $\mathrm{X} 17$ & $\begin{array}{c}\text { The uniqueness of the } \\
\text { destination }\end{array}$ & $1=$ affected; $0=$ unaffected \\
\hline & $\mathrm{X} 18$ & Emotions at the time & 1=affected; $0=$ unaffected \\
\hline Personality trait & X19 & Willing to share & $\begin{array}{c}\begin{array}{c}1=\text { Willing to share; } 2=\text { Do not willing to } \\
\text { share }\end{array}\end{array}$ \\
\hline
\end{tabular}


Table 2. The main evaluation parameters of the four models

\begin{tabular}{c|c|c|c|c|c|c}
\hline $\begin{array}{c}\text { Model } \\
\text { Selection }\end{array}$ & $\begin{array}{c}\text { Omnibus } \\
\text { Test }\end{array}$ & -2LL & Cox \& Snell R2 & Nagelkerke R2 & $\begin{array}{c}\text { Hosmer \& } \\
\text { Lemeshow } \\
\text { Test }\end{array}$ & $\begin{array}{c}\text { Predicting } \\
\text { discrimination }\end{array}$ \\
\hline Model 1 & .955 & $133.015^{\mathrm{a}}$ & .005 & .008 & .756 & $82.9 \%$ \\
\hline Model 2 & .001 & $109.699^{\mathrm{a}}$ & .152 & .253 & .968 & $84.9 \%$ \\
\hline Model 3 & .000 & $83.737^{\mathrm{a}}$ & .290 & .483 & .045 & $90.4 \%$ \\
\hline Model 4 & .000 & $78.506^{\mathrm{a}}$ & .315 & .525 & .280 & $89.7 \%$ \\
\hline
\end{tabular}

\section{RESULTS AND DISCUSSION}

\subsection{Sample Characteristics}

In terms of gender options, women are higher than men, accounting for $71.7 \%$. The number of students in freshman accounted for $17.7 \%$, sophomore $10 \%$, junior $23.9 \%$, senior year $48.42 \%$. The number of respondents with monthly income below $2000 \mathrm{RMB}$ is about for $48.42 \%, 2000-5000 \mathrm{RMB}$ is for $25.8 \%$, above 5000 RMB is for $11.3 \%$. The number of people who travel 1-2 times a year accounted for $71 \%$, travel more than 3times a year accounted for $29 \%$.

\subsection{Logical Regression Analysis of Tourism Sharing Behaviours}

According to Table 1, it is assumed that the 19 explanatory variables mentioned above were the main factors affecting tourism sharing behaviours. Therefore, the binary logistic regression method of statistical software SPSS25.0 and the idea of hierarchical regression were adopted. 19 explanatory variables were stratified into the regression model according to four dimensions, in order to gain the best regression model.

Model 1 included demographic characteristics of college students, containing explanatory variables $\mathrm{X} 1$, $\mathrm{X} 2, \mathrm{X} 3$ and $\mathrm{X} 4$.

Model 2 included demographic characteristics and individual cognitive factors of college students participants, naming the explanatory variable $\mathrm{X} 1, \mathrm{X} 2, \mathrm{X} 3, \mathrm{X} 4, \mathrm{X} 5, \mathrm{X} 6$.

Model 3 included demographic characteristics, individual cognitive factors and external conditions, naming explanatory variables X1, X2, X3, X4, X5, X6, $\mathrm{X} 7$, by $8, \mathrm{X} 9, \mathrm{X} 10, \mathrm{X} 11, \mathrm{X} 12, \mathrm{X} 13, \mathrm{X} 14, \mathrm{X} 15, \mathrm{X} 16$, $\mathrm{X} 17, \mathrm{X} 18$.

Model 4 included demographic characteristics, individual cognitive factors, external conditions and personality characteristics, containing explanatory variables X1, X2, X3, X4, X5, X6, X7, by 8, X9, X10, $\mathrm{X} 11, \mathrm{X} 12, \mathrm{X} 13, \mathrm{X} 14, \mathrm{X} 15, \mathrm{X} 16, \mathrm{X} 17, \mathrm{X} 18, \mathrm{X} 19$.

Through regression analysis, the relevant evaluation parameters of the four models were shown in Table 2. The relevant parameters evaluation results were compared as follows: (1) Except for Model 1, the Omnibus test of the remaining three models were all less than 0.05, indicating that Model 2, Model 3 and Model 4 established based on this module were very significant. (2) - 2LL term reflects the error items of all independent variables for the problem of the variation part that cannot be explained by the dependent variable. The smaller the absolute value is, the greater the likelihood value of the regression equation, the better the fitting degree of the model. It could be seen from the table that the absolute value of -21l of Model 4 was the minimum and the best fitting degree. (3)Cox \& Snell R2 and Nagelkerke R2 are statistic used to evaluate the overall effectiveness of the model. They are quantitative indicators of the proportion of change explained in the regression model. Among them, Cox \& Snell R2 is an R2 explanatory logistic regression model that simulates linear regression based on likelihood value, taking generally less than 1 . Nagelkerke R2 is a further adjustment of Cox \& Snell R2 to make its value range between $0-1$. If the values of the two indexes are greater than 0.2 , it is acceptable; if the value is greater than 0.4 , the model fitting degree is quite good. As could be seen from the data in the table, the fitting degree of Model 4 was higher than that of the other three models. (4)The zero hypothesis of the Hosmer-Lemeshow test is to divide the sample data into 10 groups based on the predicted probability, and to construct the chi-square according to the observed frequency and expected frequency. If the $p$-value is less than the given significance level, the null hypothesis will be rejected, indicating that there is a significant difference between the predicted value and the observed value. If the pvalue is greater than the given significance level, the null hypothesis will not be rejected. It could be seen from Table 2 that Hosmer-Lemeshow test of the four models all met the requirements. (5) The predictive accuracy of discrimination is mainly used to compare the ratio of logical regression to the ratio of pure random classification of elements. When the value is higher than the random ratio, it is an acceptable level. The random ratio was $66.4 \%$, and the judgment ratios of the four models were all higher than the random ratio, among which the prediction accuracy of Model 3 was the highest.

In conclusion, Model 4 was the best model for this study. Through 19 variables in Model 4, it could be 
predicted whether to carry out tourism sharing with the highest accuracy. In order to find out the independent variable that had the greatest influence on the dependent variable among the existing variables, this paper further adopted the stepwise regression method for Model 4 to gradually introduce the independent variable that has significant influence on the dependent variable with the probability of $\mathrm{P}$ value less than 0.05 . Through stepwise regression analysis, as shown in Table 3, four variables involved the regression equation: X7(network status), $\mathrm{X} 11$ (personal privacy) and X13(tourist destination experience) and $\mathrm{X} 19$ (willingness to share), while the influence of other variables did not reach a significant level. It was worth noting that this paper adopted the idea of hierarchical regression, so the final selected variable interpretation force was significantly based on the data obtained on the basis of controlling the influence of the relevant variables. The 15 variables that did not reach the significant level did not mean that there is no influence on travel sharing behavior in the single state, but shown that when the four variables, $\mathrm{X} 7$, $\mathrm{X} 11, \mathrm{X} 13, \mathrm{X} 19$, were used to explain tourism sharing behavior, the explanatories of the other variables were weak enough to could not explain the dependent variables. However, they still played the role of controlling variables in the model. Because of the existence of these variables, the explanatories of these four variables on college students' travel sharing behaviors were the data obtained by controlling the influence of the other variables in Model 4.

Table 3. Logical regression model parameters

\begin{tabular}{c|c|c|c|c|c}
\hline $\mathrm{Y}$ & B Value & S.E. & Wald & Sig. & $\operatorname{Exp}(\mathrm{B})$ \\
\hline $\mathrm{X} 7$ & 1.214 & .545 & 4.971 & .026 & 3.367 \\
\hline $\mathrm{X} 11$ & -1.441 & .530 & 7.388 & .007 & .237 \\
\hline $\mathrm{X} 13$ & 1.266 & .581 & 4.744 & .029 & 3.548 \\
\hline $\mathrm{X} 19$ & -1.829 & .522 & 12.260 & .000 & .161 \\
\hline
\end{tabular}

\section{CONCLUSION}

\subsection{Research Conclusions}

According to the results of this study, Model 4 (including demographic characteristics variables, individual cognitive variables, external environment variables and personality traits variables) had the strongest explanatory strength for whether college students conducted tourism sharing behaviours on the WeChat platform. In addition, after controlling the influence of other variables, the variables that had statistically significant influence on whether college students engaged in travel sharing on the WeChat platform include the network status, personal privacy, travel destination experience and whether individuals wanted to engage in tourism sharing. That is to say, the combination of these four variables had the most obvious explanatory for tourism sharing behaviours. In the other words, among the 19 possible influencing variables, these four variables were the most important in explanatory.

\subsection{Practical inspiration}

Positive tourism experience sharing is a natural publicity word-of-mouth. Tourism destinations and tourism enterprises should pay more attention to the impact of tourists' sharing behaviours on their own reputation and find ways to promote tourists to share positive travel experiences.

\subsubsection{Operation and Management}

Tourist destinations should provide corresponding supporting facilities for tourists to carry out online travel sharing. Such as, providing wireless network in the rest area, setting up mobile phone charging devices such as shared charging bank. In addition, VLOG and other video shooting equipment should be provided to rent to facilitate tourists to share tourism experience.

How to enhance the public praise, quality service and brand credibility should be noticed. When managing the tourism sites, the tourism enterprise operators should pay attention to collecting tourist feedback, respond to the good comments, listen to the opinions in a timely manner and contact the bad comments immediately. Although the treatment options mostly happened after the tourism, the concern for tourists would make tourists feel that they were valued, improved their favorable impression to the relevant tourist destinations and tourism businesses, and enhanced their tourism experience.

It was important to pay attention to user privacy protection and convert users who were willing to share. For users who were willing to share could be considered transforming into a "We Media" public account, so that their sharing could transform from short words in circle of friends to a fine long tweet. It benefitted to enhance the quality of travel sharing and activate the WeChat community atmosphere.

\subsubsection{Marketing Strategies}

Tourist destinations and merchants should make full use of WeChat official account, a new communication medium, to push tweets and open ticket shopping and other related services after tourists pay attention to the WeChat official account. Optimizing the production of tourism experience tweets was also an important means for tourism destinations to build their own image. When users yearn for or agree with the content of tweets, they would carry out sharing activities such as forwarding.

Material rewards are also important factor affecting tourists' information sharing. Lottery activities could stimulate users' travel sharing behavior. The forwarding 
lotteries on platforms such as Moments, which not only increased the communication degree of tourism merchants, but also strengthened the interaction with tourists. Compared with the traditional communication activities, the forwarding lotteries made the communication object directly became the content participants. Out of the desire for rewards, users would take the initiative to understand the content and commodity information of the activity and the communication effect had been improved.

Tourist destinations and tourism businesses should attach importance to the role of opinion leaders, and hired appropriate opinion leaders to publicize their tourist destinations and tourism products, so as to encourage users to make positive comments and forward the tourism contents published by opinion leaders.

\section{ACKNOWLEDGMENTS}

This research was funded by the Fujian Provincial Philosophy and Social Science Research Project (Grant No: JAS20320), Xiamen Humanities and Social Science Base Research Project (Grant No: [2021] B28) and Talent Support Program of Xiamen University of Technology (Grant No: XPDST19013, XPDST20001).

\section{REFERENCES}

[1] ZHANG Yinyu, LI Wu. A study on the influencing factors of college students' WeChat sharing behavior [J]. Southeast Communication,2015(9), PP.79-81.DOI:10.13556/j.cnki.dncb.cn35$1274 / \mathrm{j} .2015 .09 .026$

[2] YU Peipei. Study on the Motivation and Preference of College Students' WeChat Sharing Behavior [J]. Management observation, 2017(14), PP.121-123. DOI: 10.3969/j.issn.1674-2877.2017.14.046.

[3] HE Yue. Showing and Hiding: An Analysis of College Students' WeChat Information Sharing Willingness [D]. Henan University,2018.

[4] HUO Yanhua, JIN Lu. Empirical Research on Influencing Factors of WeChat Users' Information Sharing Behavior: An Information Ecology Perspective $[\mathrm{J}]$. Technology Intelligence Engineering,2019,5(3),pp.74-85.

DOI:10.3772/j.issn.2095-915x.2019.03.007

[5] N. Scott, E. Laws. Knowledge Sharing in Tourism and Hospitality [J]. Journal of Quality Assurance in Hospitality \& Tourism,2006,7(1-2),pp.1-12. DOI: 10.1300/J162v07n01_01

[6] K.H. Yoo, U. Gretzel. Influence of personality on travel-related consumer-generated media
creation[J]. Computers in Human Behavior, 2011,27(2),PP.609-621.DOI: 10.1016/j.chb.2010.05.002

[7] A.M. Munar, J.K.S. Jacobsen. Motivations for sharing tourism experiences through social media[J].Tourism Management,2014,43,PP.46-54. DOI: 10.1016/j.tourman.2014.01.012

[8] T.B.J. Kumar, S.K. Goh, M.S. Balaji. Sharing travel related experiences on social media Integrating social capital and face orientation [J]. Journal of Vacation Marketing,2021,27(2),pp.168186. DOI: $10.1177 / 1356766720975047$

[9] X. Lehto, W. Luo, L. Miao, R.F. Ghiselli. Shared tourism experience of individuals with disabilities and their caregivers $[\mathrm{J}]$. Journal of Destination Marketing \& Management,2018,8,PP.185-193. DOI: $10.1016 /$ j.jdmm.2017.04.001

[10] GAO Jiachen, FAN Jiali, ZHANG Weiya, XU Zilin. Research on Tourist Sharing Behavior on e WOM [J].Jiangsu Science \& Technology Information, 2016(8),PP.66-68.DOI: 10.3969/j.issn. 1004-7530.2016.08.026

[11] WANG Xiaorong, PENG Lifang, Li Qinyu. Research on the behavior of sharing travel experience in social media [J]. Management Review,2017,29(2),PP.97-105.

DOI:10.14120/j.cnki.cn11-5057/f.2017.02.009

[12] ZHAO Qinqin, ZHANG Meng, FU Xiaorong. The Influence of Monetary Incentives on Knowledge Re-sharing Intention in Online Travel Communities [J]. Tourism Tribune, 2018, 33(3), PP.39-49. DOI: 10.3969/j.issn.1002-5006. 2018.03. 009

[13] CHEN Yingying, LIN Derong. Research on tourism sharing behavior of strong-tie network mobile social platform-Data analysis based on WeChat and QQ users[J]. Tourism Tribune, 2020, 35(4), pp.89-103. DOI: 10.19765/j.cnki.10025006.2020 .04 .011 